\title{
MR-Symposium in Rumänien
}

Südlich von Constanța, einer geschichtsträchtigen Hafenstadt am Schwarzen Meer, fand vom 27. bis 28. Mai 2016 in Eforie Nord das rumänisch-deutsche Symposium zum Thema „Imaging Approaches for Head and Neuro Oncologic and Nononcologic Pathology" statt. Auf der mit 120 Teilnehmern gut besuchten Veranstaltung zählten neben Prof. Dammann, Leiter der DRG-Arbeitsgemeinschaft Kopf-Halsdiagnostik, auch Prof. Lupescu (Bukarest), Dr. Ionescu (Bukarest) und Prof. Santa (Sibiu) zu den Referenten. Für 2017 wurde bereits eine weitere gemeinsame Veranstaltung ver-

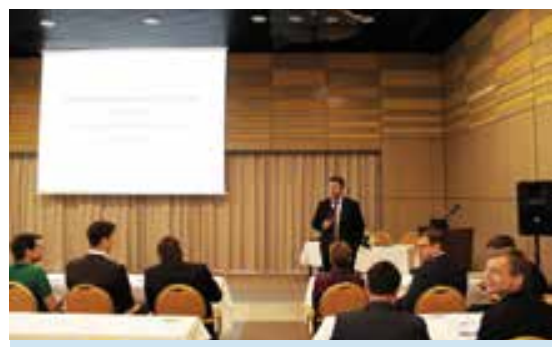

Hochkarätige Referenten machten das Symposium zu einem großen Erfolg. einbart, die voraussichtlich wieder am letzten Mai-Wochenende stattfinden wird.

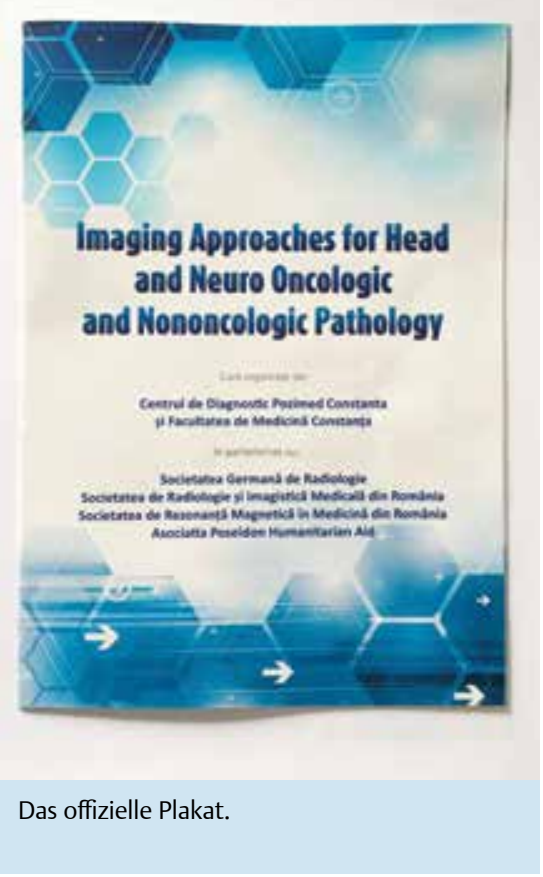

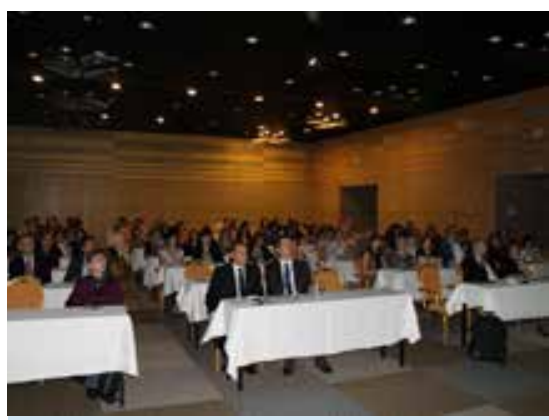

120 Teilnehmer nahmen am Symposium teil.

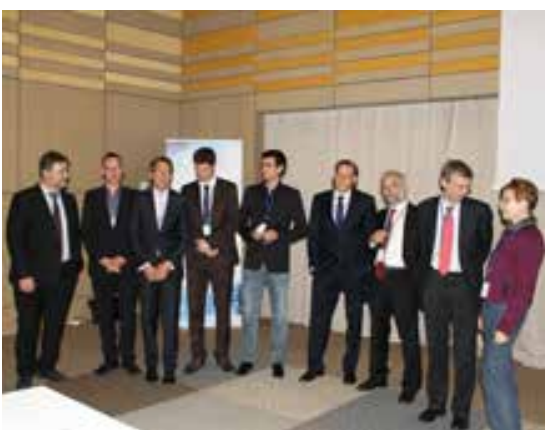

von links nach rechts: Prof. Baz (Constanta), Dr. Fleck (Neurochirurgie Greifswald), Dr. Rathmann (Radiologie Greifswald), Dr. Spoerl (Radiologie Greifswald), PD Dr. Langner (Radiologie Greifswald), PD Dr. Mensel (Radiologie Greifswald), Prof. Santa (Radiologie Sibiu), Prof. Damann (Radiologie Bern), Prof. Lupescu (Radiologie Bukarest) 